\title{
Plasma vascular non-inflammatory molecule 3 is associated with gastrointestinal acute graft-versus-host disease in mice
}

\author{
Na Wang ${ }^{1 \dagger}$, Xiaoyi Qin ${ }^{1+}$, Yigeng $\mathrm{CaO}^{2 \dagger}$, Bin Liang ${ }^{3}$, Kang $\mathrm{Yu}^{3}$ and Haige $\mathrm{Ye}^{3^{*}}$ (D)
}

\begin{abstract}
Background: Gastrointestinal acute graft-versus-host disease (Gl aGVHD) is a lethal complication following allogeneic hematopoietic stem cell transplantation (HSCT). However, it is still very difficult to make a diagnosis of GI aGVHD in practice. To date, no consensus plasma biomarker of Gl aGVHD can be used to help make a diagnosis. Here, we attempted to identify GI aGVHD associated plasma proteins in murine model, which can help make a diagnosis of Gl aGVHD.

Methods: We used 8-plex isobaric tags for relative and absolute quantitation (8-plex iTRAQ) to screen out proteins in plasma samples taken from murine models before and after allogeneic HSCT. Next mRNA expressions were validated by quantitative real-time polymerase chain reaction in mouse intestinal epithelial samples.

Results: We found that five proteins were increased at least 2-fold in the allogeneic group at day 7 compared with days 0,3 and 15 (after Cyclosporin A treatment) and the syngeneic group at day 7. These 5 proteins were VNN3, ZNF746, C4BP, KNG1 and FETUB, and they were consistent with results from negative labeling with 8-plex iTRAQ. Furthermore, increase in mRNA level of VNN3 was confirmed in murine intestinal epithelial samples with aGVHD.

Conclusions: Our results demonstrate that plasma VNN3 protein is associated with Gl aGVHD in murine model.

Keywords: Gastrointestinal, Acute graft-versus-host-disease, Plasma protein, Vascular non-inflammatory molecule 3, Mice
\end{abstract}

\section{Background}

Acute graft-versus-host-disease (aGVHD), a lethal complication after allogeneic hematopoietic stem cell transplantation (allo HSCT), contributes to high nonrelapse mortality [1]. The gastrointestinal (GI) tract is one of the most susceptible organs to aGVHD, and isolated GI involvement is under consideration by researchers [2]. A diagnosis of GI aGVHD is traditionally based on clinical manifestations and endoscopic biopsy [3]. Manifestations of GI aGVHD is characterized by watery diarrhea, nausea, anorexia and abdominal

\footnotetext{
* Correspondence: haigeye@gmail.com

${ }^{\dagger}$ Equal contributors

${ }^{3}$ Department of Hematology, The First Affiliated Hospital of Wenzhou Medical University, Nan Bai Xiang Street, Ouhai District, Wenzhou, Zhejiang 325002, China

Full list of author information is available at the end of the article
}

cramps, but these non-specific symptoms may mimic infection [3, 4]. Digestive endoscopy is often restrained by poor general patient health after HSCT, and crypt apoptosis in a mucosal biopsy is not specific for GI aGVHD. [4] Cytomegaloviral (CMV) infection, immunosuppressive medications and other comorbidities may resemble aGVHD histologically $[5,6]$, complicating the diagnosis of GI aGVHD versus other comorbidities [7].

A serological protein test would be convenient for diagnosis and valuable for predicting clinical outcomes. McDonald's group used several proteins to predict severe GI aGVHD and non-relapse mortality, such as T-cell immunoglobulin and mucin-domain containing-3, soluble tumor necrosis factor-alpha, interleukin 1 receptor-like 1 and interleukin -6 [8]. Additionally, James and colleagues discovered that regenerating islet- 
derived 3-alpha in the peripheral blood of patients after allo HSCT as an optional biomarker for diagnosing GI aGVHD before onset [9]. Thus, variations in GI GVHD biomarkers have been reported by different institutions.

Recently, 8-plex isobaric tags for relative and absolute proteomic quantitation (8-plex iTRAQ) has enabled us to identify several biomarker candidates differentially expressed in GI aGVHD patients [10]. However, lots of confounding factors exist in patients' samples. Thus, we used the mouse models for screening plasma biomarkers of aGVHD to reduce confounding factors. In present study, we used 8-plex iTRAQ proteomic tools to screen out differentially expressed plasma proteins in mouse aGVHD models and identified 5 potential biomarkers: vascular non-inflammatory molecule 3 (VNN3), zinc finger protein 746 (ZNF746), C4b-binding protein (C4BP), kininogen-1 (KNG1) and fetuin (FETUB). Furthermore, these 5 mRNA expressions were tested with real-time polymerase chain reaction (Real-Time PCR) in murine intestinal epithelial samples and VNN3 mRNA expression was validated for GI GVHD. However, confirmation in clinical patient plasma samples for VNN3 is needed.

\section{Methods}

\section{Mouse model}

Male BALB/C $(\mathrm{H}-2 \mathrm{~d})$ and $\mathrm{C} 57 \mathrm{BL} / 6 \mathrm{~J}(\mathrm{H}-2 \mathrm{~b})$ mice were purchased from the Chinese Academy of Medical Sciences (HFK, Beijing, China) and housed in groups of five in individually specific pathogen-free barrier facilities. During procedures, animals were kept under a laminar flow hood. Animal diet was standardized pellet chow and UV decontaminated water. All animal work was performed under approved ethical guidelines.

\section{Bone marrow transplantation (BMT)}

Recipient mice (BALB/C, 8 to 11 weeks-of-age) received 8 Gy of total body irradiation $\left({ }^{137} \mathrm{Cs}\right)$ delivered in two fractions separated by $4 \mathrm{~h}$ to reduce GI toxicity. One day afterward, recipients were treated with injected $1 \times 10^{7}$ BM cells (iv) supplemented with $3 \times 10^{7}$ donor spleen cells from age-matched allogeneic donor $\mathrm{C} 57 \mathrm{BL} / 6 \mathrm{~J}$ or syngeneic donor BALB/C mice. The allogeneic group consisted of 9 mice undergoing allo-HSCT, and the auto group included 12 mice undergoing auto HSCT.

\section{Assessment of aGVHD}

GVHD severity was assessed with a clinical GVHD scoring system [11] every 2 days and included weight loss, posture, activity, fur texture and skin integrity. At the time of analysis, mice from coded cages were evaluated and graded from 0 to 2 for each criterion. A clinical index was subsequently generated by summation of the five criteria scores (maximum index $=10$ ). As for GI
aGVHD, we added diarrhea to these five criteria for diagnosis. Survival was monitored on a daily basis.

\section{Monitor hematopoietic reconstitution}

Blood tests were carried out 3 times a week and evaluation of hematopoietic reconstruction, weight, leukocyte counts exceeding $0.5 \times 10^{9} / \mathrm{L}$, or the presence of donorderived cells was done. Peripheral blood (PB) cells from mice in aGVHD and control groups were stained with $\mathrm{PE}$ anti-H-2d and PE-Cy5.5 anti-H-2b (eBioscience, San Diego, CA) as described [12]. FACS CantoII (BD Biosciences, San Jose, $C A$ ) were used to acquire data which were analyzed with BD FACSDiva software (BD Biosciences, San Jose, CA).

\section{Histopathology}

Small intestine biopsies were taken from mice at various time points after transplantation. Tissues were placed in $10 \%$ buffered formalin phosphate and fixed tissues were paraffin-embedded, sectioned, and stained with H\&E. Slides were coded without reference to prior treatment and examined in a blinded fashion by two pathologists.

\section{CsA, LPSs and PBSs administration}

CsA (Cyclosporin A, Novartis PharmaSchweiz AG, Switzerland, $20 \mathrm{mg} / \mathrm{kg}$ ) was intraperitoneally (ip) administered daily to aGVHD mice. LPS (lipopolysaccharide from E. coli, Sigma, MO, USA) was administered (ip, $5 \mu \mathrm{g})$ to two auto-graft recipients at day 11 posttransplantation. Phosphate-Buffered Saline (PBS, Sigma, MO, USA) was administered (ip) daily to two auto-graft recipients at day 11 post-transplantation.

\section{Samples preparation}

Plasma and intestinal biopsy specimens were collected from mice using a random approach (allogeneic and syngeneic groups) after animals were cervical dislocated at days 0 (after conditioning and prior to transplantation), 3, and 7 (allogeneic group developed aGVHD and CsA was given, ip), day 11 (syngeneic group PBS or LPS, ip), day 15 (CsA was discontinued in the allogeneic group), day 22 (CsA was given for mice with relapsed aGVHD in the allogeneic group), and day 30.

\section{Removal of high-abundance proteins}

A Seppro IgY-M7 antibody SpinColumn (Sigma, MO, USA) was used to remove the 7 most highly abundant proteins in murine plasma, including albumin, IgG, fibrinogen, transferring, IgM, haptoglobin, and $\alpha-1$ antitryptase. According to instructions, the low abundant protein samples were prepared from plasma samples. 


\section{Protein concentration assay}

Plasma protein was measured using a BCA Protein Assay Kit. After quantification, each sample containing $40 \mu \mathrm{g}$ protein was preserved at $-80^{\circ} \mathrm{C}$.

\section{Tryptic digestion and iTRAQ labeling}

Plasma sample containing $20 \mu \mathrm{g}$ protein were denatured with buffer 1 ( $8 \mathrm{M}$ carbamide $+100 \mathrm{mM}$ Tris-HCL), and to this was added $4 \mu$ l reducing reagent $(100 \mathrm{mM}$ dithiothreitol, Amresco, OH, USA) at $37^{\circ} \mathrm{C}$ for $2 \mathrm{~h}$, alkylated with freshly prepared cysteine-blocking reagent (500 mM iodacetamide, Amresco, OH, USA) at room temperature for $15 \mathrm{~min}$, and the protein solution was centrifuged at 12,000 rpm for $20 \mathrm{~min}$ and the solution at the bottom was collected. Then, to this was added $100 \mu \mathrm{l}$ buffer 2 (500 mM triethylammonium bicarbonate buffer, Sigma, MO, USA), centrifuged at 12,000 for $10 \mathrm{~min}$, supernatant was discarded and solution at the bottom was collected. This was repeated three times. Subsequently, protein was incubated with $40 \mu \mathrm{l}$ sequencing grade modified trypsin (Promega, WI, USA) at $50 \mathrm{ng} / \mu \mathrm{l}$ and $100 \mu \mathrm{l}$ buffer 2 at $37^{\circ} \mathrm{C}$ for $16 \mathrm{~h}$.

Digested samples were labeled with iTRAQ reagents (SCIEX, MA, USA) twice (positive and negative). Briefly, one vial of 8-plex iTRAQ labeling reagent (i.e., $\mathrm{m} / \mathrm{z} 113$, $114,115,116,117,118,119,121)$ was used for every $100 \mu \mathrm{g}$ protein. Positive labeling and negative labeling were shown in Additional file 2. First, iTRAQ reagent was solubilized in $70 \mu \mathrm{l}$ of isopropanol and then to this was added to $100 \mu \mathrm{g}$ protein sample for $2 \mathrm{~h}$. Next, labeling was terminated with $100 \mu \mathrm{l}$ of water. Then, $1 \mu \mathrm{l}$ of sample was withdrawn from every protein sample and desalinated with Ziptip and identified by MALDI-TOF/ TOF to assure labeling was successful. After identification, samples were then mixed at equal ratios and dried with vacuum freeze-drying.

\section{Protein separation and identification}

Labeled proteins were separated with high $\mathrm{pH}$ reversed phase chromatography using a C18 trapping column (ZORBAX Extend C18, $100 \AA 2.1 \times 150 \mathrm{~mm}$ ) at a flow rate of $0.3 \mathrm{ml} / \mathrm{min}$ and the wavelengths used were 215 and $280 \mathrm{~nm}$. Lyophilized proteins were dissolved in Nano-RPLC buffer A (2\% acetonitrile/water containing $0.1 \%$ formic acid), desalted onto a C18 precolumn $(100 \mu \mathrm{m} \times 3 \mathrm{~cm}, \mathrm{C} 18,3 \mu \mathrm{m}, 150 \AA)$ for $10 \mathrm{~min}$ at $2 \mu \mathrm{L} /$ min, and analyzed on EksigentnanoLC-Ultra ${ }^{\mathrm{T}} 2 \mathrm{D}$ system (SCIEX, Beijing, China). Subsequently, the protein were analyzed on a nano-reverse-phase LC system (RPLC), using a C18 reversed phase chromatograph column (75 $\mu \mathrm{m} \times 15 \mathrm{~cm} \mathrm{C18}-3 \mu \mathrm{m} 120 \AA$, ChromXPEksigent), and Nano-RPLC buffer B (98\% acetonitrile/water containing $0.1 \%$ formic acid) was increased from $5 \sim 38 \%$ in
70 min. Data were calculated using Protein Pilot Software v. 4.5 (SCIEX, MA, USA).

\section{Validation in intestinal epithelial samples by quantitative real-time PCR}

Total RNA from mice recipients in different groups at different interval times were extracted by TRIzol (Invitrogen, Carlsbad, CA, USA). RNA concentration and quality were quantified by measuring the absorbance at $260 \mathrm{~nm}$ with Thermo Scientific ${ }^{\mathrm{Tw}}$ NanoDrop ${ }^{\mathrm{Tw}}$ spectrophotometer (Thermo Scientific, Wilmington, DE, USA) and gel analysis. Relative expression was calculated using the $2^{-\triangle \Delta C T}$ method. The primers of VNN3 and other gene transcripts were designed by Primer Express Software v2.0. $\beta$ - actin housekeeping gene was used for normalization.

\section{Reproducibility}

Experiments were repeated at least 2 times with 3 sample replicates; To analyze one variable in one BMT experiment, at least two groups of 5 recipients are required.

\section{Statistical analysis}

Bars and error bars represent the means and standard errors of the mean, respectively. An ANOVA test was used to evaluate the difference between each two different groups. A $p$ value $<0.05$ or 0.001 was considered to be statistically significant. Statistical analyses were performed using GraphPad Prism software (Irvine, CA).

\section{Results}

\section{Construction of Gl aGVHD mouse model}

HSCs from donor mice were transplanted into irradiated recipient mice as described and mice were divided into allogeneic and syngeneic groups. Seven days after transplantation, mice in the allogeneic group had characteristic aGVHD, including hair loss, skin lesions, hunched postures, diarrhea and weight loss. Significant differences in bodyweight and aGVHD scores relative to syngeneic mice were observed from day 4 onward. The bodyweights of mice in the allogeneic group were significantly lower than those in the control group at day $7(P<0.05)$. Similarly, the aGVHD scores of allogeneic transplantation mice differed from the scores of the syngeneic transplantation mice; the gap between the aGVHD scores in the allogeneic and syngeneic groups was largest at day $7(P<0.001)$ (Fig. 1a and b). WBC and Neutrophil counts at days 6 and 22 were significantly elevated compared with that at other time points in allogeneic group. Especially at day 6, WBC and Neutrophil counts reached the peak (Fig. 4a and b). Flow cytometry data (Additional file 1) showed nearly 100\% of PB cells from mice in the allogeneic group were donor-derived at day 7, which confirmed successful reconstruction of hematopoiesis with donor HSCs. Additionally, 

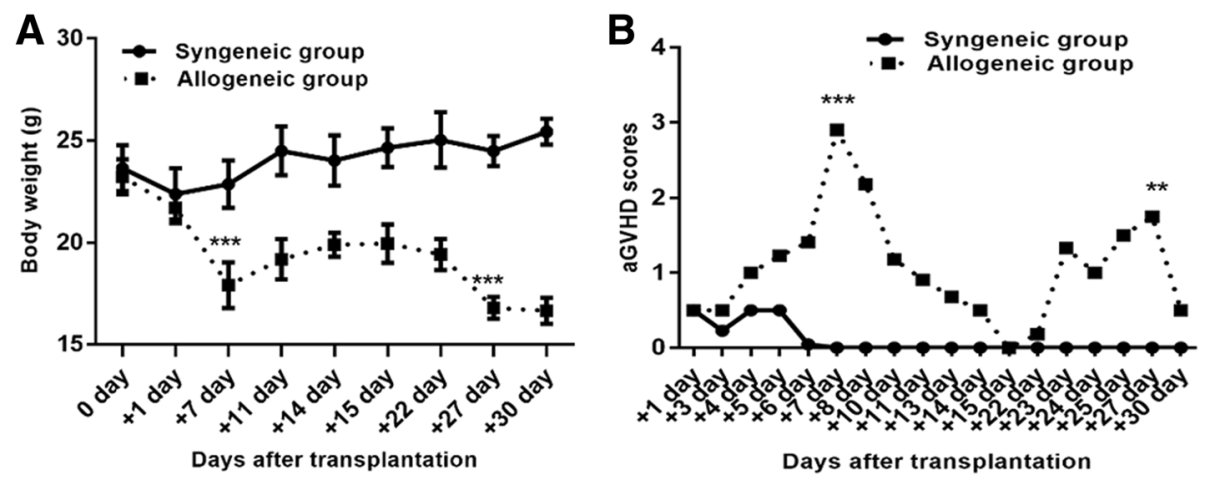

Fig. 1 aGVHD was induced in recipient mouse with allogeneic HSCT compared with syngeneic HSCT. a Weight changes of recipient mice at different time-points. b GVHD scores evaluated in allogeneic and syngeneic groups at different time-points after transplant. ${ }^{* *} P<0.05$; ${ }^{* * *} P<0.001$. Bars and error bars represent the means and standard errors of the mean, respectively. $n=5$ mice per time point per group

histological examinations of intestines demonstrated lymphocyte infiltration in the aGVHD group (day 7) but not in the control group (Additional file 1) and histological scoring analysis revealed different impairment patterns of intestine (Fig. 2) [13, 14]. Then, CsA was administered (ip) daily to aGVHD mice until the allogeneic group was in remission at day 15. The aGVHD relapsed at day 22, and mice received CsA and went into remission again. In contrast, the syngeneic group had a significantly lower aGVHD score than the allogeneic group during the entire observation period of 30 days (Fig. 1b). Mice that received LPS or PBS had no aGVHD symptoms. Thus, we successfully constructed the GI aGVHD murine models after allogeneic HSCT.

Differential expression of proteins in GI aGVHD identified by 8-plex iTRAQ labeling and MALDI-TOF/TOF

We used 8-plex iTRAQ to identify candidate biomarkers in murine plasma samples taken before and after the

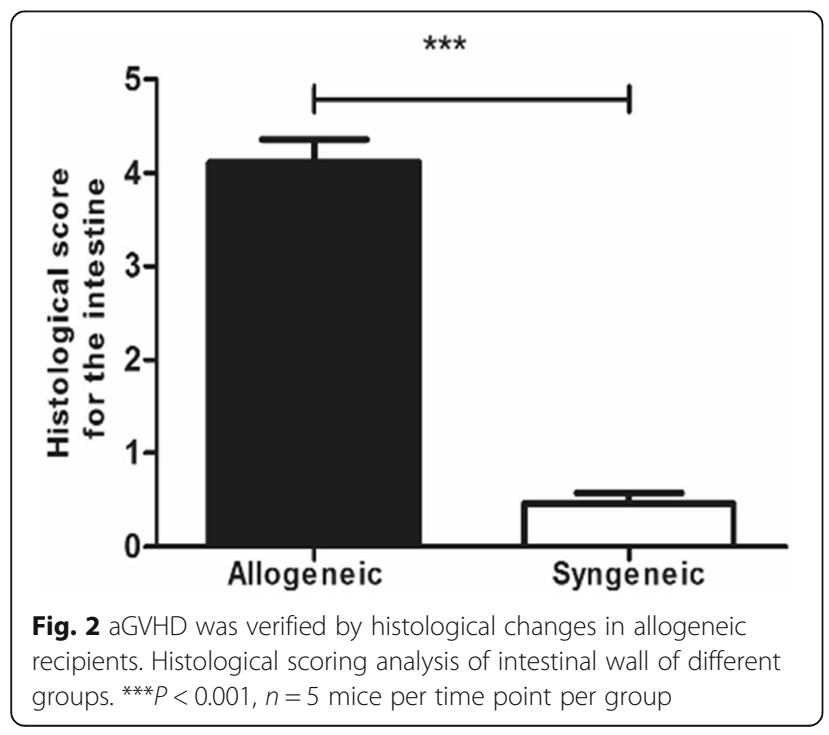

onset of aGVHD. We identified and quantified 712 proteins of which 5 were increased at least 2-fold in the allogeneic group at day 7 compared with days 0,3 and 15 (after CSA treatment) and the syngeneic group at day 7 (Additional file 2). These 5 proteins were VNN3, ZNF746, C4BP, KNG1 and FETUB, and they were consistent with results from negative labeling with 8-plex iTRAQ (Additional file 2).

These five plasma proteins in the allogeneic group increased at the onset of GI aGVHD (day 7), and decreased with remission of GI GVHD after CSA treatment. Furthermore, proteins peaked at day 7, whereas aGVHD symptoms were the most evident at day 7 . Compared to the allogeneic group, the five plasma proteins in the syngeneic group did not change appreciably.

In addition, LPS was given to the auto group at day 11 to simulate infectious intestinal milieus. Similar protein was observed in LPS treated and PBS control mice. Protein in the allogeneic group at day 7 during GI aGVHD was greater than that in the syngeneic group treated with LPS at day 11. Thus, these five elevated proteins may not be caused by pathogens such as LPS.

\section{Validation by real-time PCR in intestinal epithelial samples}

To determine whether the five plasma proteins of interest agreed with gene expression data in intestinal epithelial cells, we obtained intestinal epithelial specimens to measure VNN3, ZNF746, C4BP, KNG1 and FETUB gene expression using Real-Time PCR. Kinetic changes in VNN3 expression in the intestinal epithelial cells were consistent with protein expression in plasma (Fig. 3a). [15] According to the results of Real-Time PCR, the VNN3 level of allogeneic group fluctuated as the occurrence and remission of GI aGVHD as well. It has a 2.7fold increase at the time of aGVHD at day 7 in allogeneic group as compared with corresponding time point of control syngeneic group $(p<0.001)$. After CSA 


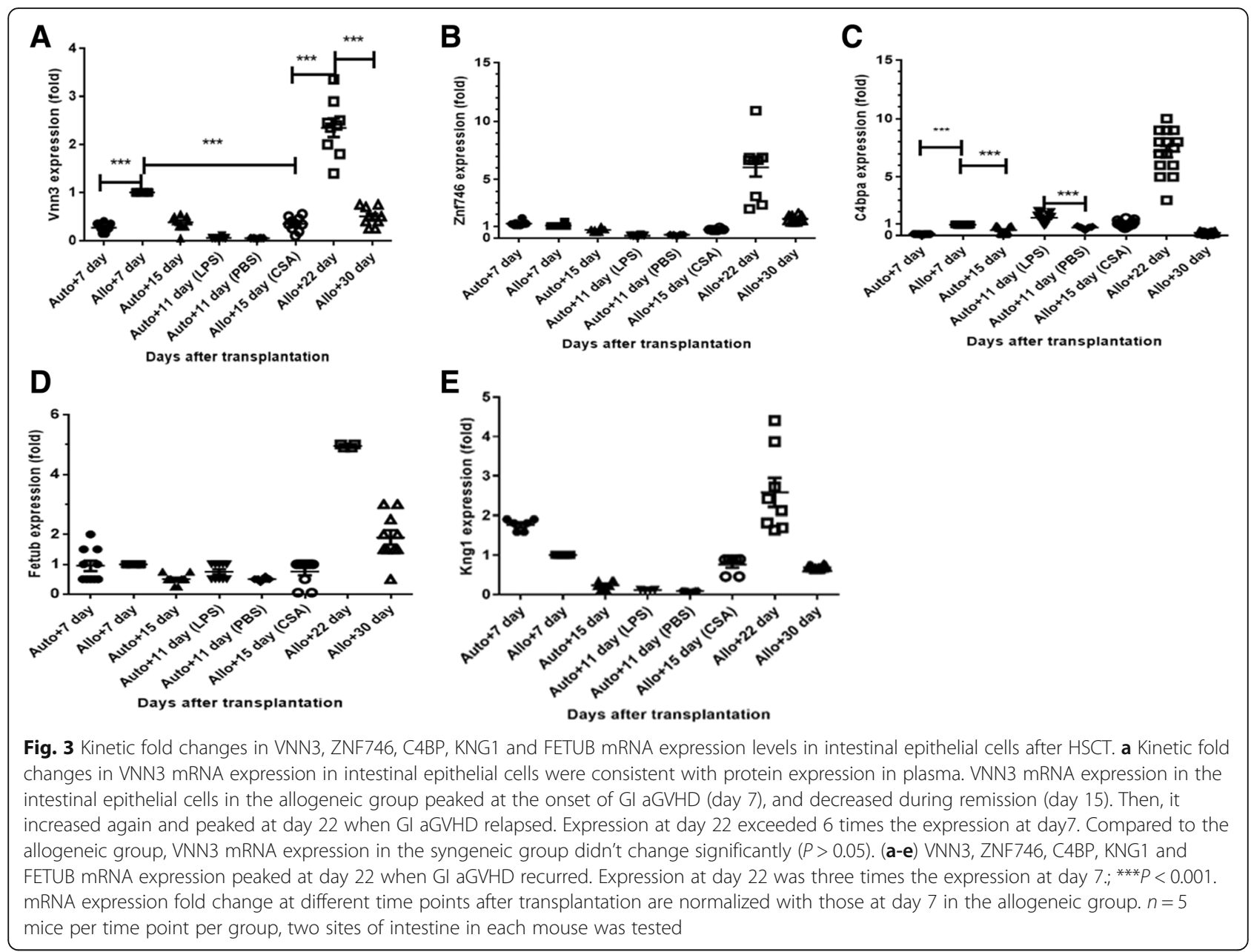

treatment at day 15 of allogeneic group, the VNN3 level decreased 1.8-fold $(\mathrm{p}<0.001)$.When the GI aGVHD relapsed at day 22, the level of VNN3 increased to 2.6 times as against day $15(p<0.001)$. By contraries, the VNN3 level of syngeneic group at day 11(after LPS injection) was merely 0.26 times as against day 7 in autogroup $(p>0.05)$. Also, PBS could not cause significant increase of VNN3 level (0.2-fold) as compared with day 7 in syngeneic group $(p>0.05)$.

Besides, the expression of gene VNN3, ZNF746, C4BP, KNG1 and FETUB achieved the peak at day 22 when the GI aGVHD recurred and were more than 3 times as those at day 7(Fig. 3a-e). In our study, the count of WBC especially neutrophil at day 22 is much more than that at day 7 as well (Fig. 4a and b). However, kinetic changes of RNA ZNF746, C4BP, KNG1 and FETUB levels were not consistent with those changes in plasma (Fig. 3b-e).

\section{Discussion}

The complicated pathophysiology of GI aGVHD is accompanied by breaches in the GI mucosa and pathogen transduction, allo-reactivity of $\mathrm{T}$ cells, inflammation, and tissue damage and repair [3, 16-18]. We report here that five differential expression of plasma proteins VNN3, ZNF746, C4BP, KNG1 and FETUB between aGVHD+ and aGVHD- plasma samples in mouse model. All five plasma proteins VNN3, ZNF746, C4BP, KNG1 and FETUB have not been described in GI aGVHD in previous studies. These five plasma proteins were screened by relative and absolute quantitation proteomic technology (8-plex iTRAQ), which can increase analytical throughput while reducing experimental error and improve peptide ionization [10, 19]. Nevertheless, few published studies suggested iTRAQ proteomic tools for searching aGVHD biomarkers in plasma samples. Furthermore, VNN3 gene expression was validated in intestinal epithelial samples by RealTime PCR (Fig. 3a). Thus, elevated plasma VNN3 may be produced by damaged GI epithelial cells when aGVHD occurred.

VNN3, a Vanin family member encoding pantetheinase isoforms, hydrolyzes pantetheine into pantothenic acid (vitamin B5) and cysteamine, which is an antioxidant 

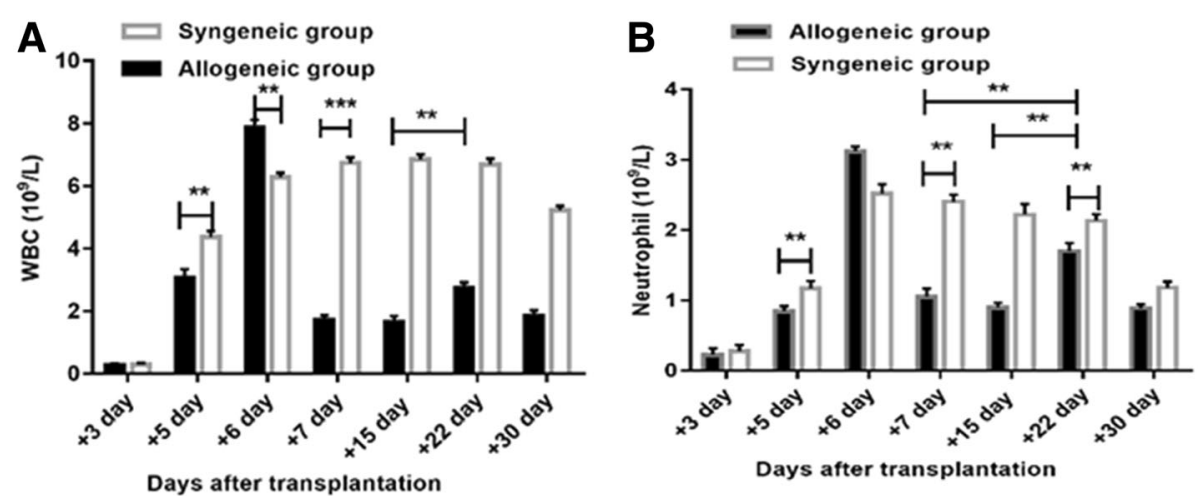

Fig. $4 \mathrm{WBC}$ and neutrophil count changes after transplantation in mice. By day 7, recipients in the allogeneic group developed leukopenia, with a 5.5 -fold reduction in the WBC count $(P<0.001)(\mathbf{a})$ and a 3.0-fold reduction in the neutrophil count $(P<0.05)(\mathbf{b})$ compared with the syngeneic group. At day 22 in allogeneic group, the WBC and neutrophil count were recovered up to about 1.7-fold and 1.9-fold, respectively, in comparison with those in day $15(P<0.05)$. ${ }^{*} P<0.05 ;{ }^{* *} P<0.001$. Bars and error bars represent the means and standard errors of the mean, respectively. $n=5$ mice per time point per group

$[20,21]$. In vivo, pantothenic acid requires transformation into coenzyme-A to metabolize proteins, carbohydrates and fats. Nitto's group found alternative spliced variants of VNN3 in leukocytes lysates, especially in neutrophils [22]. Also, VNN3 is an ectoenzyme and can be secreted by neutrophils [21-23], which cause inflammation in transplanted organs. Recently, neutrophils have been reported to have analogous function to antigen presenting to lymph nodes and promoting differentiation of T cells, such as APCs [24, 25].

Of note, in our study, neutrophil counts reached the peak at day 6 upon the fulminant aGVHD and reached the second peak at day 22 with the relapsed aGHVD (Fig. 4b). The initial breaches to the GI mucosal barrier may be caused by the conditioning regimen allows translocation of potent inflammatory stimuli such as LPS, high Mobility Group Box-1 (HMGB-1) and other pathogen-associated molecular patterns [3, 26-28], which bind to Toll-like receptor in neutrophils and trigger activation and production of ectoenzyme [3, 26, 27]. To "tackle" the inflammatory cascade upstream, in some cases, LPS and HMGB-1 could be eliminated by AN69 membranes in dialysis [29].

Therefore, VNN3 increases in $\mathrm{PB}$ and its products pantothenic acid and cysteamine increase subsequently to provide the requisite energy and anti-oxidation with oxidative status of neutrophils $[16,30]$. Thus, at the onset of GI aGVHD, expression of VNN3 in intestinal epithelial cells increased and as the intestinal epithelium was damaged, intracellular synthetic VNN3 protein was released and increased in the plasma, which may provide protection effect. In addition, VNN3 expression was decreased after CSA treatment in our study, which indicates VNN3 plasma protein may have value not only as a noninvasive diagnostic biomarker but also as an evaluative index for treatment effect. Furthermore, VNN3 expression was not increased after LPS administration, which may be helpful for differentiation of aGVHD from infection.

Although the kinetics of the other 4 RNAs (ZNF746, C4BP, KNG1 and FETUB) expression in intestinal epithelial cells in our Real-Time PCR test are not coordinated with plasma changes, these proteins had concordant changes between positive and negative 8-plex iTRAQ labelling. Hence, these four plasma proteins may be also involved in the "cytokine storm" of aGVHD. ZNF746, a substrate of parkin that plays a role in innate immune defense mechanisms, [31] may assist in preventing GI aGVHD which can be triggered by innate immunity $[3,26,27,32]$. Because of the consumption of parkin in GI aGVHD, ZNF746 can be upregulated. C4BP inhibits activation of the complement cascade, which offers antiinflammatory activity in GI aGVHD with complex pro-inflammatory milieus [33]. FETUB is implicated in the production of TNF- $\alpha$ and IL-6 that are key to the pathophysiology of GI aGVHD [34-36]. KNG1 was reported to contribute to experimental intestinal and systemic inflammation and high KNG1 may damage tissue and may be upregulated in GI aGVHD [37].

As shown in Fig. 3a-e, gene expression of VNN3, ZNF746, C4BP, KNG1 and FETUB peaked at day 22. Meanwhile, neutrophils counts at day 22 also markedly exceeded that on day 7 (Fig. 4b, $p<0.05$ ). Accordingly, neutrophils might cause much more inflammation in GI at day 22 that other time points. Several studies indicate that neutrophils proliferate and migrate to the GI tract where they cause tissue damage and promote the development of GI aGVHD [38-41]. Neutrophils, cleaving chemokines and producing reactive oxygen species, promote activation of $\mathrm{T}$ cells and consequently aggravate GI aGVHD [42]. A detailed pathologic study indicated that greater neutrophils density in the full thickness of the 
lamina propria were associated with worse clinical outcome [39]. All of these studies strongly suggest that neutrophils are correlated with the severity of inflammation damage.

\section{Conclusions}

Plasma VNN3 protein is associated with GI aGVHD in mouse models. In addition, matching differential expression of plasma protein with corresponding gene expression in intestinal epithelium indicates the high likelihood of replacing intestinal biopsy with noninvasive plasma biomarker. In future studies, we will validate VNN3 with ELISA in patient plasma samples to determine their significance with respect to clinical outcome.

\section{Additional files}

Additional file 1: aGVHD was verified by histological changes in allogeneic recipients. (A and B) Donor-derived cells in the allogeneic group were measured by flow cytometry at day 7 to confirm implantation of donor. (C) H\&E staining of mouse small intestine tissues in the allogeneic group on day 7. Small intestinal mucous villi degenerate and denude. (D) H\&E staining of mouse small intestinal tissues of mice in the syngeneic group on day 7 . Small intestinal mucosa had no obvious pathological changes. $n=5$ mice per time point per group. (DOC $3783 \mathrm{~kb}$ )

Additional file 2: Positive ITRAQ label of proteins with increased levels in day 7 in allogeneic group with aGVHD.8-plex iTRAQ approach is that the relative quantification is achieved via the difference in abundance of the reporter product ions (i.e., $\mathrm{m} / \mathrm{z} 113,114,115,116,117,118,119,121$ ). For positive labeling, 115 was day 0, 114 was day 3 (allogeneic group), 116 was day 7 (syngeneic group), 117 was day 7 (allogeneic group), 118 was day 11 (syngeneic group ip PBS), 119 was day 11 (syngeneic group ip LPS), and 121 was day 15 (after CsA treatment in allogeneic group), 113 was labeled day 22 (syngeneic group). Differential protein levels between aGVHD+ and aGVHD- from eight time points were evaluated for 117/115, $117 / 114,117 / 116,117 / 121,117 / 118,117 / 119$ and $117 / 113$ sets, respectively, with the ratio more than 2.0 defined as increased. (DOC $48 \mathrm{~kb}$ )

\section{Abbreviations}

aGVHD: Acute graft-versus-host-disease; allo-HSCT: Allogeneic hematopoietic stem cell transplantation; C4BP: C4b-binding protein; CMV: Cytomegaloviral; CSA: Cyclosporin A; FETUB: Fetuin; Gl: Gastrointestinal; Ip: Intraperitoneally; ITRAQ: Isobaric tags for relative and absolute quantitation; KNG1: Kininogen1; LPS: Lipopolysaccharide; PBS: Phosphate-buffered saline; PCR: polymerase chain reaction; VNN3: Vascular non-inflammatory molecule 3; ZNF746: Zinc finger protein 746

\section{Acknowledgements}

We thank LetPub (www.letpub.com) for its linguistic assistance during the preparation of this manuscript.

\section{Funding}

This work was supported by the Zhejiang Provincial Natural Science Foundation of China under Grant [LY13H080003 and LY12H08002], and Wenzhou Municipal Sci-Tech Bureau's program under Grant [Y20120045].

\section{Availability of data and materials}

The data are all presented in the manuscript.

\section{Authors' contributions}

NW, XYQ, YGC and HGY assisted in design and experimental research, analyzed and interpreted data, and contributed in writing manuscript; NW, XYQ and YGC performed the animal model, 8-plex iTRAQ labeling and RealTime PCR work; BL and KY contributed to discussion of results; HGY designed study, interpreted data, and developed the manuscript. All authors read and approved the final manuscript.

\section{Ethics approval}

All experimental procedures were approved by the animal research ethics committee of Institute of Hematology and Blood Diseases Hospital, Chinese Academy of Medical Sciences and Peking Union Medical College.

\section{Consent for publication}

Not applicable.

\section{Competing interests}

The authors declare that they have no competing interests.

\section{Publisher's Note}

Springer Nature remains neutral with regard to jurisdictional claims in published maps and institutional affiliations.

\section{Author details}

${ }^{1}$ Wenzhou Medical University, Wenzhou, Zhejiang 325002, China. ${ }^{2}$ Institute of Hematology and Blood Diseases Hospital, Chinese Academy of Medical Sciences and Peking Union Medical College, Tianjin 300020, China.

${ }^{3}$ Department of Hematology, The First Affiliated Hospital of Wenzhou Medical University, Nan Bai Xiang Street, Ouhai District, Wenzhou, Zhejiang 325002, China

Received: 7 June 2017 Accepted: 20 December 2017

Published online: 05 January 2018

\section{References}

1. Gooley TA, Chien JW, Pergam SA, Hingorani S, Sorror ML, Boeckh M, Martin PJ, Sandmaier BM, Marr KA, Appelbaum FR, et al. Reduced mortality after allogeneic hematopoietic-cell transplantation. N Engl J Med. 2010;363:2091-101.

2. Martin PJ, McDonald GB, Sanders JE, Anasetti C, Appelbaum FR, Deeg HJ, Nash RA, Petersdorf EW, Hansen JA, Storb R. Increasingly frequent diagnosis of acute gastrointestinal graft-versus-host disease after allogeneic hematopoietic cell transplantation. Biol Blood Marrow Transplant. 2004;10:320-7.

3. Ferrara JL, Levine JE, Reddy P, Holler E. Graft-versus-host disease. Lancet. 2009:373:1550-61.

4. Kambham N, Higgins JP, Sundram U, Troxell ML. Hematopoietic stem cell transplantation: graft versus host disease and pathology of gastrointestinal tract, liver, and lung. Adv Anat Pathol. 2014;21:301-20.

5. Snover DC. Mucosal damage simulating acute graft-versus-host reaction in cytomegalovirus colitis. Transplantation. 1985:39:669-70.

6. Parfitt JR, Jayakumar S, Driman DK. Mycophenolate mofetil-related gastrointestinal mucosal injury: variable injury patterns, including graftversus-host disease-like changes. Am J Surg Pathol. 2008;32:1367-72.

7. Lorenz F, Marklund S, Werner M, Palmqvist R, Wahlin BE, Wahlin A. Fecal calprotectin as a biomarker of intestinal graft versus host disease after allogeneic hematopoietic stem cell transplantation. Sci Rep. 2015;5:7920

8. McDonald GB, Tabellini L, Storer BE, Lawler RL, Martin PJ, Hansen JA. Plasma biomarkers of acute GVHD and nonrelapse mortality: predictive value of measurements before GVHD onset and treatment. Blood. 2015:126:113-20.

9. Ferrara JL, Harris AC, Greenson JK, Braun TM, Holler E, Teshima T, Levine JE, Choi SW, Huber E, Landfried K, et al. Regenerating isletderived 3-alpha is a biomarker of gastrointestinal graft-versus-host disease. Blood. 2011;118:6702-8.

10. Ye H, Sun L, Huang X, Zhang P, Zhao X. A proteomic approach for plasma biomarker discovery with 8-plex iTRAQ labeling and SCX-LC-MS/MS. Mol Cell Biochem. 2010;343:91-9.

11. Lin Y, Hu X, Cheng H, Pang Y, Wang L, Zou L, Xu S, Zhuang X, Jiang C, Yuan $W$, et al. Graft-versus-host disease causes broad suppression of hematopoietic primitive cells and blocks megakaryocyte differentiation in a murine model. Biol Blood Marrow Transplant. 2014;20:1290-300.

12. Iwasaki T, Hamano T, Saheki K, Kuroiwa T, Kataoka Y, Takemoto Y, Ogata A, Sugihara A, Terada N, Fujimoto J, Kakishita E. Effect of graft-versus-host disease (GVHD) on host hematopoietic progenitor cells is mediated by FasFas ligand interactions but this does not explain the effect of GVHD on donor cells. Cell Immunol. 1999;197:30-8. 
13. Pan B, Zeng L, Cheng H, Song G, Chen C, Zhang Y, Li Z, Xu K. Altered balance between Th1 and Th17 cells in circulation is an indicator for the severity of murine acute GVHD. Immunol Lett. 2012;142:48-54.

14. Pan B, Zhang Y, Sun Y, Cheng H, Wu Y, Song G, Chen W, Zeng L, Xu K. Deviated balance between Th1 and Th17 cells exacerbates acute graftversus-host disease in mice. Cytokine. 2014;68:69-75.

15. Livak KJ, Schmittgen TD. Analysis of relative gene expression data using real-time quantitative PCR and the 2(-Delta Delta C(T)) method. Methods. 2001:25:402-8

16. Penack O, Holler E, van den Brink MR. Graft-versus-host disease: regulation by microbe-associated molecules and innate immune receptors. Blood. 2010;115:1865-72.

17. Zhang L, Chu J, Yu J, Wei W. Cellular and molecular mechanisms in graftversus-host disease. J Leukoc Biol. 2016;99:279-87.

18. Ferrara JL, Deeg HJ. Graft-versus-host disease. N Engl J Med. 1991;324:667-74.

19. Bouchal P, Roumeliotis T, Hrstka R, Nenutil R, Vojtesek B, Garbis SD. Biomarker discovery in low-grade breast cancer using isobaric stable isotope tags and two-dimensional liquid chromatography-tandem mass spectrometry (iTRAQ-2DLC-MS/MS) based quantitative proteomic analysis. J Proteome Res. 2009:8:362-73.

20. Lin ZY, Chuang WL. Pharmacologic concentrations of ascorbic acid cause diverse influence on differential expressions of angiogenic chemokine genes in different hepatocellular carcinoma cell lines. Biomed Pharmacother. 2010;64:348-51.

21. Martin F, Malergue F, Pitari G, Philippe JM, Philips S, Chabret C, Granjeaud S, Mattei MG, Mungall AJ, Naquet P, Galland F. Vanin genes are clustered (human 6q22-24 and mouse 10A2B1) and encode isoforms of pantetheinase ectoenzymes. Immunogenetics. 2001;53:296-306.

22. Nitto T, Inoue T, Node K. Alternative spliced variants in the pantetheinase family of genes expressed in human neutrophils. Gene. 2008;426:57-64.

23. Jansen PA, Kamsteeg M, Rodijk-Olthuis D, van Vlijmen-Willems IM, de Jongh GJ, Bergers M, Tjabringa GS, Zeeuwen PL, Schalkwijk J. Expression of the vanin gene family in normal and inflamed human skin: induction by proinflammatory cytokines. J Invest Dermatol. 2009;129:2167-74.

24. Beauvillain C, Cunin P, Doni A, Scotet M, Jaillon S, Loiry ML, Magistrelli G, Masternak K, Chevailler A, Delneste Y, Jeannin P. CCR7 is involved in the migration of neutrophils to lymph nodes. Blood. 2011;117:1196-204.

25. Scozzi D, Ibrahim M, Menna C, Krupnick AS, Kreisel D, Gelman AE. The role of Neutrophils in transplanted organs. Am J Transplant. 2017;17:328-35.

26. Hill GR, Ferrara JL. The primacy of the gastrointestinal tract as a target organ of acute graft-versus-host disease: rationale for the use of cytokine shields in allogeneic bone marrow transplantation. Blood. 2000;95:2754-9.

27. Ye H, Lv M, Zhao X, Zhao X, Huang X. Plasma level of lipopolysaccharide-binding protein is indicative of acute graft-versushost disease following allogeneic hematopoietic stem cell transplantation. Int J Hematol. 2012;95:680-8.

28. Nogueira-Machado JA, de Oliveira Volpe CM. HMGB-1 as a target for inflammation controlling. Recent Pat Endocr Metab Immune Drug Discov. 2012;6:201-9.

29. Yumoto M, Nishida O, Moriyama K, Shimomura Y, Nakamura T, Kuriyama N, Hara Y, Yamada S. In vitro evaluation of high mobility group box 1 protein removal with various membranes for continuous hemofiltration. Ther Apher Dial. 2011;15:385-93.

30. Amer J, Weiss L, Reich S, Shapira MY, Slavin S, Fibach E. The oxidative status of blood cells in a murine model of graft-versus-host disease. Ann Hematol. 2007:86:753-8

31. Manzanillo PS, Ayres JS, Watson RO, Collins AC, Souza G, Rae CS, Schneider DS, Nakamura K, Shiloh MU, Cox JS. The ubiquitin ligase parkin mediates resistance to intracellular pathogens. Nature. 2013;501:512-6.

32. Konya $\mathrm{V}$, Mjosberg J. Innate lymphoid cells in graft-versus-host disease. Am J Transplant. 2015;15:2795-801.

33. Hofmeyer T, Schmelz S, Degiacomi MT, Dal Peraro M, Daneschdar M, Scrima A, van den Heuvel J, Heinz DW, Kolmar H. Arranged sevenfold: structural insights into the C-terminal oligomerization domain of human C4b-binding protein. J Mol Biol. 2013;425:1302-17.

34. Zhang K, Huang XZ, Li XN, Feng M, Li L, Cai XJ, Zhang C, Liu XL, Zhang MX Zhang $Y$, et al. Interleukin 6 destabilizes atherosclerotic plaques by downregulating prolyl-4-hydroxylase alpha1 via a mitogen-activated protein kinase and c-Jun pathway. Arch Biochem Biophys. 2012;528:127-33.

35. Morris ES, Hill GR. Advances in the understanding of acute graft-versus-host disease. Br J Haematol. 2007;137:3-19.
36. Galis ZS, Muszynski M, Sukhova GK, Simon-Morrissey E, Unemori EN, Lark MW, Amento E, Libby P. Cytokine-stimulated human vascular smooth muscle cells synthesize a complement of enzymes required for extracellular matrix digestion. Circ Res. 1994;75:181-9.

37. Isordia-Salas I, Pixley RA, Sainz IM, Martinez-Murillo C, Colman RW. The role of plasma high molecular weight kininogen in experimental intestinal and systemic inflammation. Arch Med Res. 2005;36:87-95.

38. Klambt V, Wohlfeil SA, Schwab L, Hulsdunker J, Ayata K, Apostolova P. Schmitt-Graeff A, Dierbach H, Prinz G, Follo M, et al. A novel function for P2Y2 in myeloid recipient-derived cells during graft-versus-host disease. J Immunol. 2015;195:5795-804.

39. Socie G, Mary JY, Lemann M, Daneshpouy M, Guardiola P, Meignin V, Ades $L$, Esperou H, Ribaud P, Devergie $A$, et al. Prognostic value of apoptotic cells and infiltrating neutrophils in graft-versus-host disease of the gastrointestinal tract in humans: TNF and Fas expression. Blood. 2004;103:50-7.

40. Giroux M, Delisle JS, Gauthier SD, Heinonen KM, Hinsinger J, Houde B, Gaboury L, Brochu S, Wu J, Hebert MJ, Perreault C. SMAD3 prevents graftversus-host disease by restraining Th1 differentiation and granulocytemediated tissue damage. Blood. 2011;117:1734-44.

41. Schwab L, Goroncy L, Palaniyandi S, Gautam S, Triantafyllopoulou A, Mocsai A, Reichardt W, Karlsson FJ, Radhakrishnan SV, Hanke K, et al. Neutrophil granulocytes recruited upon translocation of intestinal bacteria enhance graft-versus-host disease via tissue damage. Nat Med. 2014;20:648-54.

42. Sena LA, Li S, Jairaman A, Prakriya M, Ezponda T, Hildeman DA, Wang CR, Schumacker PT, Licht JD, Perlman $\mathrm{H}$, et al. Mitochondria are required for antigen-specific T cell activation through reactive oxygen species signaling. Immunity. 2013;38:225-36.

\section{Submit your next manuscript to BioMed Central and we will help you at every step:}

- We accept pre-submission inquiries

- Our selector tool helps you to find the most relevant journal

- We provide round the clock customer support

- Convenient online submission

- Thorough peer review

- Inclusion in PubMed and all major indexing services

- Maximum visibility for your research

Submit your manuscript at www.biomedcentral.com/submit
) Biomed Central 